\title{
AN HRM SYSTEM FOR SMALL AND MEDIUM ENTERPRISES (SME)S BASED ON CLOUD COMPUTING TECHNOLOGY
}

\author{
Pavel Y. Abdullah ${ }^{1}$ iD , Subhi R. M. Zeebaree ${ }^{2}$, Karwan Jacksi ${ }^{3}$, Rizgar R. Zeabri ${ }^{* 4}$ \ \\ ${ }^{1}$ College of Engineering, Tishk International University, Kurdistan Region, Iraq \\ 2 Presidency of Duhok Polytechnic University, Duhok, Kurdistan Region, Iraq \\ ${ }^{3}$ Computer Science Dept., University of Zakho, Duhok - Kurdistan Region, Iraq \\ ${ }^{*}$ Information technology Dept., Duhok Polytechnic University, Duhok - Kurdistan Region, Iraq
}

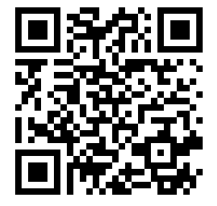

DOI: https://doi.org/10.29121/granthaalayah.v8.i8.2020.926

Article Type: Research Article

Article Citation: Pavel Y. Abdullah, Subhi R. M. Zeebaree, Karwan Jacksi, and Rizgar R. Zeabri. (2020). AN HRM SYSTEM FOR SMALL AND MEDIUM ENTERPRISES (SME)S BASED ON CLOUD COMPUTING TECHNOLOGY. International Journal of Research -GRANTHAALAYAH, 8(8), 56-64.

https://doi.org/10.29121/granthaa layah.v8.i8.2020.926

Received Date: 29 July 2020

Accepted Date: 19 August 2020

Keywords:

Human Resource

HRM

HRMS

SMEs

Cloud-Based HRM

Cloud Computing

Enterprise

\section{ABSTRACT}

Technology has changed our life and the way we work; however, technology has affected several methods of working in Small and Medium Enterprises (SME)s. Human Resource (HR) is one of the core components in businesses, and nowadays most businesses are using technology for daily basis tasks. However, it still is not used all over the world. In Kurdistan Region-Iraq (KRI), most of the SMEs still use the old way of working and follow the paper-based method for their daily basis tasks. According to a survey, more than seventy percent of SMEs in Kurdistan are not using software to manage human resource management tasks. However, some big companies are using HRMS; but even then, there is a lack of use of Cloud Technology. In this study, a model of the Enterprise Human Resource Management System (EHRMS) is proposed and implemented to solve the HR problems in this area using Cloud Technology. The proposed system consists of sixteen standard modules which used usually with famous HRM systems. The system has been developed by using several technologies such as CodeIgniter as a software framework. The system is launched and deployed on Amazon Web Service (AWS) Elastic Compute Cloud (EC2).

\section{INTRODUCTION}

In the new era, organizations and firms use software in order to manage company functions. One of the core components of a company is the Human Resource (HR) department. The HR department is an important component of any firm because it has several crucial functions that affect the firm directly. Training, atoning, evaluating performance, appraising staff and attending, relationship, concerning health and safety of employees are the functions of HRM [1], [2]. A Human Resource Management System (HRMS) is a system that combines several applications of managing HR tasks such as employee performance, recruiting, file management, promoting,

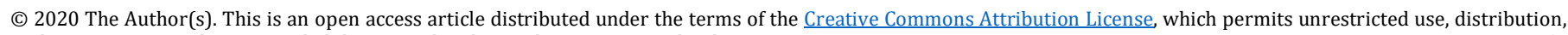
and reproduction in any medium, provided the original author and source are credited. 
complaining, resigning, etc. into one package as one system [3], [4], [5]. Many organizations are benefitted by using HRMS for systematic business procedures such as gathering and collecting, managing, receiving, and validating information and data, managing tasks and activates which are acquired by the HR department [6], [7], [8].

A Processing model which is used for administrating processing capabilities for information as a service is called Cloud Computing, information processing on the network on usage basis among several users is part of cloud technology [9], [10], [11], [12], [13]. Cloud computing has added another measurement to IT as far as provisioning of different sorts of administrations to the customer. Cloud computing is continually advancing a huge measure of capacity and computing power accessible to cloud specialist co-ops to make computing simpler for customers [14], [15]. Cloud computing can be viewed as a model that permits access to different administrations by clients onrequest anywhere [16].

The cloud computing services can be provided by several companies such as Google, Microsoft, and Amazon, Google's Cloud service called Google Cloud Platform (GCP), Microsoft's could service called Microsoft Azure, and Amazon's cloud service called Amazon Web Service (AWS). They provide different services of cloud computing technology such as Software as a Service (SaaS), Platform as a Service (PaaS), and Infrastructure as a Service (IaaS). These services allow clients to deploy their applications on a cloud that been developed by any programming languages without concerning storage, processing, and computing [16], [17], [18], [19].

HRMS can be used in cloud technology because it's also requiring a large storage to store all the data and accessing those data easily, cloud technology is good option to be used with HRMS because it offers several services such as security, scalability and increasing efficiency [20].

Therefore, this study focuses on designing and developing an HRMS, which is integrated with cloud technology in Kurdistan Region-Iraq (KRI).

\section{RELATED WORKS}

Nowadays, numerous types of researches try to oversee HRs in organizations since HR does a significant job in accomplishing higher performance for businesses are firms. Proficient HRM boosts productivity and increases the staff's ability to react to the association's update. Thus, the current literature review gives an extensive study in HR to support businesses and firms to take advantage of HRMSs and get benefits as decreasing the cost and increasing performance.

In 2015, Choochote and Chochiang, [21] presented a study on Electronic Human Resource Management (eHRM) in Phuket. They studied e-HRM in practice for the hotels. They have done surveys on the field among several hotels and HR positions.

The study concluded vary results for using component modules of e-HRM for hotels such as fifteen percent using recruitment, fifty five percent using employee management, only ten percent have association structure, and six percent of having assessment module, finally they found out most of the hotels are not ready to implement and use e-HRM.

In 2017, Weeramanthrie [22] proposed a HRM web software. The aim of presented sytstem was to estimate the turnover employees in businesses and organizations, the system works on historical data to fill some gaps among admin's abilities and staff behaviors in the past, current and even future of the association. The system was organized in oreder to be depended to analyze the current employment situation. The third step has is to analyze past employee behaviors by identifying hidden patterns from a given data set using a predictive data mining technique. The final step is displaying some results and a range regarding the performance of the employees from low to high, this plot helped admins and managers to estimate the future staff performance. They suggested that the proposed system can be applied to all organizations and firms all over the world.

In 2014, Selvi et al. [23] implemented a HRMS at Research and Development Centre for Iron \& Steel (RDCIS). The main purposes of their system were; forecasting of organizational needs, continual monitoring and adjustment of personnel systems, to take care of reducing manpower, to automate the business functions of Personnel and Administration department, and to provide faster employee services and online access to various information of the employees. The implemented system comprised five modules which were; Employee Self Profile, Dependent Declaration, Leave Management, Leave Encashment, and Tour Management module. The different modules of the application were available to the user according to the role and privileges assigned. The software has been deployed with Tomcat Apache Serve. 
Pavel Y. Abdullah, Subhi R. M. Zeebaree, Karwan Jacksi, and Rizgar R. Zeabri.

In 2009, Ying and Xiao-hui [24] designed and implemented a new high-effect, flexible, expandable enterprise HRMS framework using Java 2 Enterprise Edition (J2EE) platform technology. The proposed web-based system encompasses seven modules which are; Personnel Management, Institution Management, Post Management, Pay Management, Training Management, Performance Evaluation Management, and System Function Management. The proposed system resolves a large number of practical problems the enterprise has faced to improve HRM efficiency. The system is also simple and easy to implement, and it has strong features such as easy maintenance, easy to be expanded, flexibility, and security.

In 2017, another study in universities in South Africa presented by Randle et al. [26], The study revealed the external elements that motivate to practice Human Resource Information System (HRIS). The addressed three main factors that affect the HRIS: Ethics is the first factor that affects the organization by giving authority to who needs to access a specific data. The second element that has a great impact on the firm is organizational politics. Finally, the organizational culture is the last element for example; improving staff performance, gender equality employment, and training sessions, however, they presented a theoretic model for universities that empower staff and motivate them to have a better understanding of using HRIS correctly and get the maximum effect of it. The proposed model consisted of the modules: employee management, job fulfillment, psychological performance, commitment and assurance, and social environment.

In 2017, Vinogradova et al. [27] Did another study in Russia. This study presented an association information management system that is used for economic businesses. They studied that the development key component of an association information system is advancing automation of HRM structure. They demonstrated that sliding planning is more affected by dynamical changes than periodic planning in the marketplace. For the development technics, both internal and external elements have an impact on associations in these kinds of planning technics.

\section{METHODOLOGY AND PROPOSED SYSTEM ARCHITECTURE}

In order to develop an enterprice system, it is better to follow and work according to one of the software development methods, Agile Methodology has been followed in this study to develop the EHRMS because agile methodology has several advantages which are: high quality product, focus on business value, and flexibility of the work. Agile is one of the Software Development Life Cycle (SDLC) methods which a group of people work together and manage a project in order to develop a software by dividing into same stages which are mentioned below and continuously enhancements at every stage [28].

\subsection{PROPOSED SYSTEM REQUIREMENTS}

In order to implement the proposed system, there are main software and hardware requirements necessary to be provided.

\subsubsection{SOFTWARE REQUIREMENTS}

In order to let the proposed EHRMS work properly there are few software's which are required to be installed on the machine or instance of the cloud which are Apache server, MySQL, PHP as Programming Language, and Web browser.

\subsubsection{HARDWARE REQUIREMENTS}

Hardware is one of the key components of any system, if hardware requirements do not meet then it may cause issues or a lack of using the system. The minimum hardware requirements for the proposed mode is shown in Table 1.

Table 1: Hardware Requirements

\begin{tabular}{|c|c|}
\hline \multicolumn{2}{|c|}{ Minimum Hardware Requirements } \\
\hline Processor Speed & $1.8 \mathrm{GHz}$ \\
\hline Hard Disk & $200 \mathrm{~GB}$ \\
\hline
\end{tabular}


An HRM System for Small and Medium Enterprises (Sme)S Based on Cloud Computing Technology

\begin{tabular}{|l|l|}
\hline RAM & $3 \mathrm{~GB}$ \\
\hline
\end{tabular}

\subsection{DESIGN STRUCTURE OF THE PROPOSED EHRMS}

The structure of the system is focused on, the structure of any enterprise system is a complex and extensive structure because it consists of several software's, hence it's called enterprise system, the structure of the proposed EHRMS is also complex because human resource(HR) department has several functions and the system has to store all the data of those functions. The EHRMS consist of 16 modules which are Staff Management, Core of HR, Organization Module, Timesheet management, Payroll Management, Training Management, Performance Management, Recruitment Management, Calendar Management, Ticket Management, File Management, Project Management Asset management, Events \& Meeting Management, Reports Management and System Configuration as shown Figure 1.

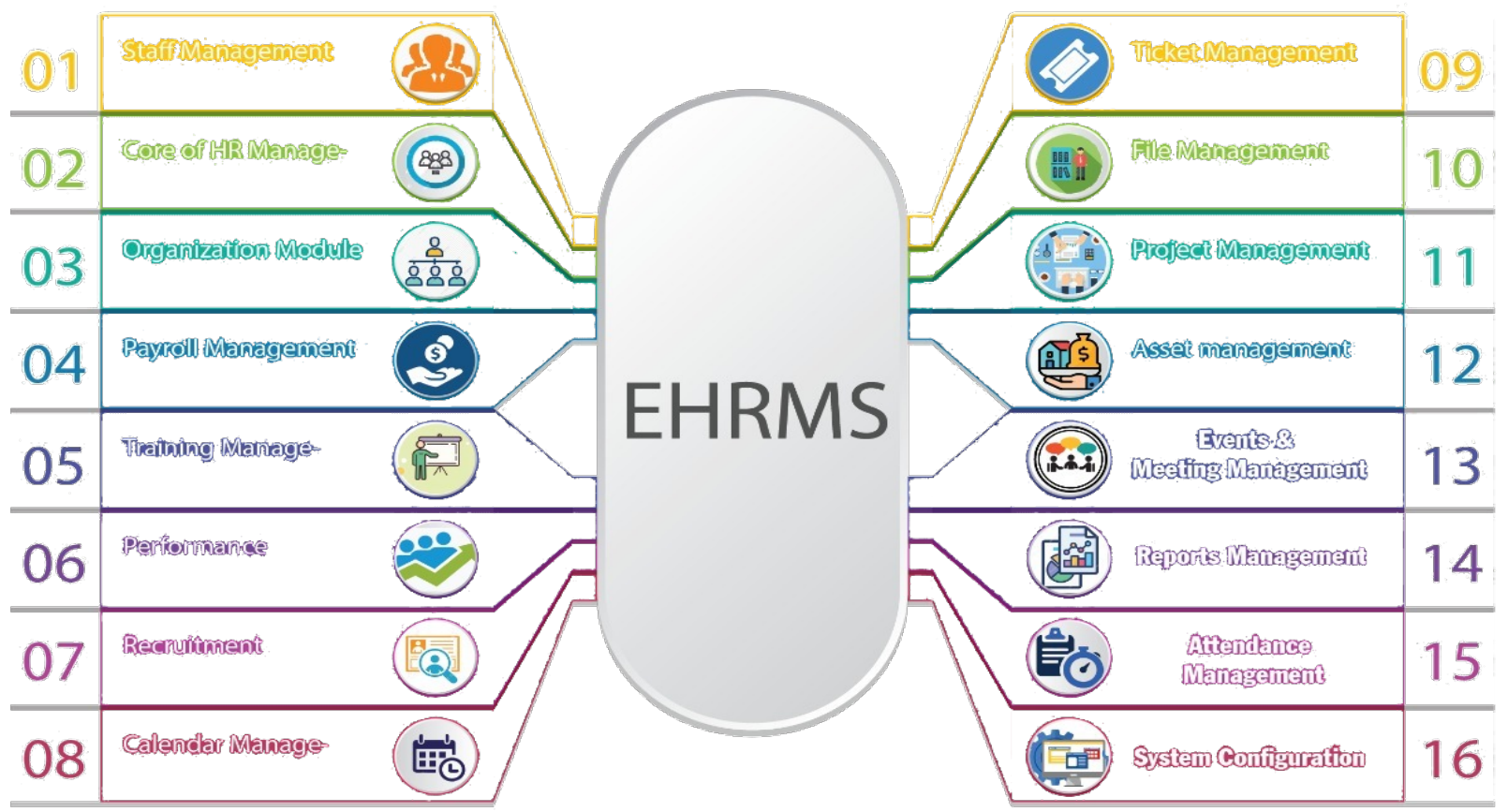

Figure 1: Modules of Proposed EHRMS

\subsection{FRONT- END OF THE PROPOSED SYSTEM}

Front-end is one of the components of any software in which users interact with front-end directly, it's crucial that the front-end should be designed user-friendly, colors, element sizes, responsiveness, fonts and font size should be relevant and complete each other.

\subsection{BACKEND \& DATABASE OF PROPOSED EHRMS}

An EHRMS requires a big database because it stores huge data for several modules among chunk of employees. The database of proposed EHRMS is big because it consists of 131 tables and stores a huge data every day for several HR functions and many employees.

\section{PROTOTYPE IMPLEMENTATION}

This section concentrates on the implementation of the proposed EHRMS. It provides the technical side of the proposed EHRMS in detail depending on the SDLC as mentioned. The proposed EHRMS will ensure viable use and most extreme improvement of human resources, create and keep up human resource records and permit the 
Pavel Y. Abdullah, Subhi R. M. Zeebaree, Karwan Jacksi, and Rizgar R. Zeabri.

appropriate actions and properly access to precise data to the individuals who require the data. This section consists of the following sections, which are implementing modules of EHRMS, integration with AWS cloud and evaluation of EHRMS.

\subsection{IMPLEMENTING MODULES OF EHRMS}

The following section concentrates on each module in advance with providing specifications and screenshots. The Core of HR module is considering closely to main HR functions such as Awards, Transfers, Resignations, Travels, Promotions, Complaints, Warnings and Terminations. HRM allows HRs to manage the mentioned functions, however allows employees to view their Awards, Transfers, Resignations, Travels, Promotions, Complaints, Warnings and Terminations. Some of HR functions are displayed on the system.

Organization Module allows admin/HR to manage different organizations or companies and connecting all the branches together. Moreover, it lets the HRs to add departments and designations for each branch, there might be a difference between two branches for departments and designation. Also, there is a feature of this module that allows the administrator to set units inside departments, in some company's departments are divided into several units then there are designations.

Monitoring of attendance of employees is one of the HR functions which usually has been done on paper or attendance device in this area. But with the application of the system, it will allow employees to check-in and checkout through the system and calculate working hours and absent hours of each employee. Evaluation of employees is another key component of a successful organization corroborated by the fact that. On the system, admin can set indicators on indicators sub-module as pre-determined objectives, there are indicators and expected performance from the employee. The system compares those two for each indicator and allows the admin to see the difference between the actual performance of the employee and the expected performance. The method work and let the admin set evaluation of employees monthly.

Recruitment is one of the main HR functions in all businesses including Small and Medium Enterprises (SME)s. It consists of two sub-modules (Job Posts and Job Candidates). Job posts sub-module manage the vacancies of the organization/company. It allows the HRs to fill the vacancy form and provide the requirements of the vacancy. When HR adds a vacancy form, the system automatically publishes it on the home page of the organization/company website. Candidates can see the job description, published day, expire date, and number of positions. Job Candidates sub-module is managing the candidates that applied for the vacancies which are published on the website of company/organization, HRs can see Cover Letter, Name, Email, and download the candidate Curriculum Vitate (CV). Also, the advance search has been implemented in order to filter the candidates and vacancies easily.

File Management module admin and HRs can store the files and documents depending on departments of the company/ organization. Storing the files and documents on this module will keep them safe from losing those files because the admin can have multiple backups. Additionally, this module provides security for the files and documents from unauthorized people. The Project \& task manager module allows admin and project managers to manage the projects of the company/ organization. All companies and organizations have projects and activities.

It is important to have a section to organize project details such as Project Files and Documents, Project Plan, Project Invoices, Project Clients or Donors, Project Timeline, and Progress of the project. Assets are the resources of the organization/company, they are valuable and need to be kept by the organization. Some assets are given to employees in order to do tasks of the business. Assets can be lost or broken by employees. So, to manage and arrange assets of the company/ organization, this module has been developed which lets the admin or HR to organize the asset information and details.

Payroll and finance are an essential department of any business which affect the future of the company/organization. In this module, the manager can add payees and payers of salary, generate pay slips, and history of the payslips. However, managing bank accounts, deposits, withdraws, transfers and all transactions have been made within the system.

\subsection{INTEGRATION WITH AWS CLOUD}

The system has been integrated with cloud technology on Amazon Web Service (AWS) using Elastic Service Cloud (EC2). EC2 is a server from AWS Cloud Technology. EC2 has several advantages such as client does not require 
An HRM System for Small and Medium Enterprises (Sme)S Based on Cloud Computing Technology

use hardware to store data and secure them also does not need to update or upgrade the hardware because AWS EC2 automatically manage it. By using AWS EC2 for the proposed EHRMS, data streams over data centers of the AWS network in all regions and automatically secured from the physical layer.

\subsection{SECURITY OF THE PROPOSED EHRMS}

HRMS store critical and important information of an organization/company, it is vital to have some security levels on different layers for the system. In order to provide a security level between client-side and service side a Secure Socket Level (SSL) has been used, SSL transmit sensitive data such as username, password, Bank Card Number securely by providing a secure connection [29].

Encryption layers exist on EC2 such as: all VPC cross-region peering traffic, and customer or service-to-service TLS connections. Tools are provided that allow easy encryption of data in transit and at rest to help ensure that only authorized users can access it, using keys managed by AWS Key Management System (KMS) or managing Customer's encryption keys with CloudHSM using FIPS 140-2 Level 3 validated HSMs. The design of AWS EC2 global infrastructure allows retaining complete control over the regions in which the data is physically located, helping meet data residency requirements [30].

In addition, another security levels have been done internally within the system which is user credentials, no one can access the system without having username and password, also the password has been encrypted by (bcrypt) method which is a faction used to hashing passwords, moreover, In the HRMS, the access to different sections is restricted by the SuperAdmin. The SuperAdmin has the privileges to allow which sections can be added/modified by whom. Safeguards should also be in place to quickly bar terminated employees' access to systems.

\subsection{FEATURES OF PROPOSED SYSTEM}

The proposed system has several features and advantages which are:

- Accessibility: The most crucial aspect of the HRMS is the admission to the Library of data which is at fingertips at most times. Being available as a Mobile application also allows the information and tracking possible from anyplace and anytime. As the information on the system can be modified anywhere, more crucial data is captured and updated. This helps in better analysis and tracking of crucialactivities like Updating/Adding a new Event, Raising and closing tickets.

- Monitors KPIs: the proposed EHRMS allows reporting, KPI index setting and goal tracking feature $s$ to monitor and evaluate performance of an employee. It makes the employee empowered asthe goal and targets are known to them at all times.

- File Management: One of the key features of the system is the ability to upload and store files. It becomes cumbersome and laborious to keep paperwork and manually updating data fields. Efficiency and Storage space take a big hit resulting in loss of productivity. Therefore, the File manager helps in storing critical documents which can be accessed by people as decided by the Super Admin.

- Reduce Cost: Reduces paperwork. An HRMS eliminates much of the paperwork associated with HR operations. Specifically, it standardizes processes related to employee information (employment history, licenses, certifications, education, skills, performance, and compensation information etc.), hiring, changing salaries, and more.

\subsection{EVALUATION OF EHRMS}

Evaluation and Testing is one of the important steps in SDLC, in order to evaluate the System Usability Scale (SUS) has been used for the proposed EHRMS, SUS is a tool, which simply used to evaluate software, and it is a set of ten questions. The questions are multiple choices from 1 to 5 and from Strongly Disagree to Strongly Agree. Even Questions counted as negative and Odd Questions counted as Positive [31], an example of SUS questionnaire is appended to Appendix A. The evaluation process has been done by staff of Emma Organization and Kurdish-French Centre Staff. The questionnaire has been filled by 54 users for 45 days from 01/01/2020 to 15/02/2020. 
Pavel Y. Abdullah, Subhi R. M. Zeebaree, Karwan Jacksi, and Rizgar R. Zeabri.

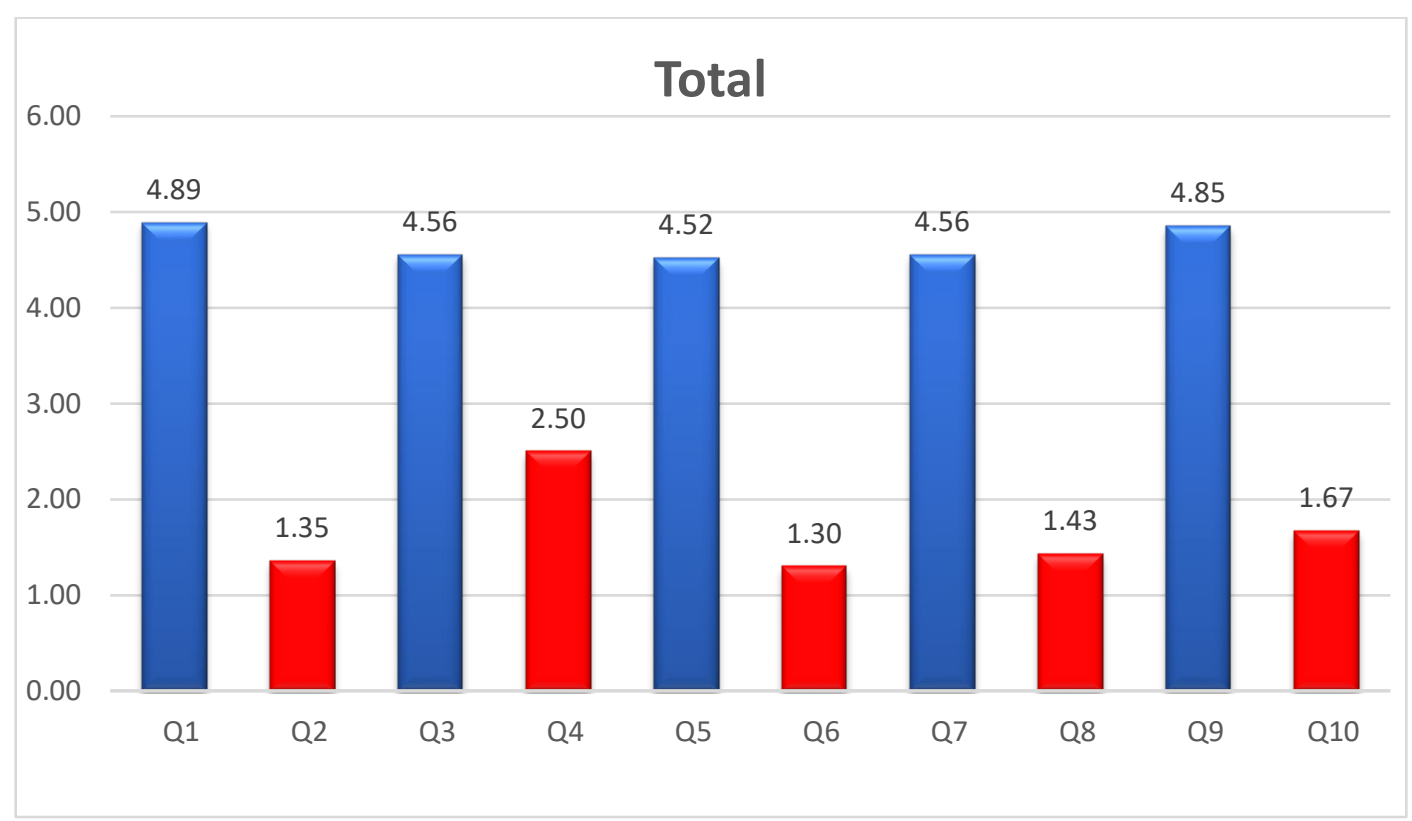

Figure 2: Average Value of Questions

The proposed EHRMS has been reviewed and evaluated for user satisfaction, proficiency and user friendly. The result of Odd questions is high which are positive values, but the result of Even questions is low as they are negative values. The average SUS Score of total questions is 35 which is equivalent to \%88, the minimum value is 1.2 and the maximum value is 4.8 as shown in Figure 2.

\section{CONCLUSIONS}

In the light of the implementation of the proposed EEHRMS, the following conclusions can be drawn:

- An efficient Enterprise Human Resource Management System (EHRMS) has been proposed, designed, and implemented. The proposed system can facilitate managing the financial and administrative affairs, project management of any Small and Medium Enterprises (SME)s and can convert the mechanisms used by their staff to an electronic approach. Consequently, it can be concluded that the proposed system will be the keystone to connect all the business branches in different geolocations to one electronic system. Also, the proposed EHRMS integrated with cloud technology and deployed in the AWS EC2 cloud service.

- The proposed EHRMS enhances the communication system between the administration and the financial directorates and units as well as the communication between branches. It also improves the communication between the staff and the departments/ units with full flexibility.

- The system is designed to save money, time, and effort. Therefore, the system can be used repeatedly in any other Enterprise System inside Iraq. In addition, it can be re-configured according to the needs of the used system in the enterprise in a short time.

\section{SOURCES OF FUNDING}

This research received no specific grant from any funding agency in the public, commercial, or not-for-profit sectors.

\section{CONFLICT OF INTEREST}

The author have declared that no competing interests exist. 
An HRM System for Small and Medium Enterprises (Sme)S Based on Cloud Computing Technology

\section{ACKNOWLEDGMENT}

None.

\section{REFERENCES}

[1] Y. He, "The Study on the Key Elements in Strategic HRM: from Strategy to Organizational Performance," in MATEC Web of Conferences, 2017, vol. 100, p. 05020.

[2] R. R. Zebari, S. R. Zeebaree, K. Jacksi, and H. M. Shukur, "E-Business Requirements for Flexibility and Implementation Enterprise System: A Review," Int. J. Sci. Technol. Res., vol. 8, no. 11, pp. 655-660, Nov. 2019.

[3] S. Williams, "The associative model of data," J. Database Mark. Cust. Strategy Manag., vol. 8, no. 4, pp. 336-359, 2001.

[4] S. R. Zeebaree, R. R. Zebari, K. Jacksi, and D. A. Hasan, "Security Approaches for Integrated Enterprise Systems Performance: A Review,” Int. J. Sci. Technol. Res., vol. 8, no. 12, Dec. 2019.

[5] S. R. Zeebaree, H. M. Shukur, and B. K. Hussan, "Human resource management systems for enterprise organizations: A review," Period. Eng. Nat. Sci., vol. 7, no. 2, pp. 660-669, 2019.

[6] N. V. Lashmanova, E. S. Fedorova, and M. A. Kossukhina, "Human resources management strategy on an innovative company: Competence approach," in 2016 IEEE V Forum Strategic Partnership of Universities and Enterprises of Hi-Tech Branches (Science. Education. Innovations), 2016, pp. 54-56.

[7] R. R. Zebari, S. R. Zeebaree, and K. Jacksi, "Impact Analysis of HTTP and SYN Flood DDoS Attacks on Apache 2 and IIS 10.0 Web Servers," in 2018 International Conference on Advanced Science and Engineering (ICOASE), 2018, pp. 156-161.

[8] S. R. Zeebaree, K. Jacksi, and R. R. Zebari, "Impact analysis of SYN flood DDoS attack on HAProxy and NLB cluster-based web servers," Indones. J. Electr. Eng. Comput. Sci., vol. 19, no. 1, pp. 510-517, 2020.

[9] V. Behal and A. Kumar, "Cloud computing: Performance analysis of load balancing algorithms in cloud heterogeneous environment," in 2014 5th International Conference-Confluence the Next Generation Information Technology Summit (Confluence), 2014, pp. 200-205.

[10] S. R. M. Z. ADEL AL-ZEBARI ALI SELAMAT, "ELECTRONIC LEARNING MANAGEMENT SYSTEM BASED ON SEMANTIC WEB TECHNOLOGY: A REVIEW," Int. J. Adv. Electron. Comput. Sci., vol. 4, no. 3, Art. no. 3, 2017.

[11] Z. N. Rashid, S. R. Zebari, K. H. Sharif, and K. Jacksi, "Distributed Cloud Computing and Distributed Parallel Computing: A Review," 2018, pp. 167-172.

[12] Z. N. Rashid, S. R. Zeebaree, and A. Shengul, "Design and Analysis of Proposed Remote Controlling Distributed Parallel Computing System Over the Cloud," in 2019 International Conference on Advanced Science and Engineering (ICOASE), 2019, pp. 118-123.

[13] D. A. Zebari, H. Haron, S. R. Zeebaree, and D. Q. Zeebaree, "Multi-Level of DNA Encryption Technique Based on DNA Arithmetic and Biological Operations," in 2018 International Conference on Advanced Science and Engineering (ICOASE), 2018, pp. 312-317.

[14] L. M. Haji, S. R. Zeebaree, O. M. Ahmed, A. B. Sallow, K. Jacksi, and R. R. Zeabri, "Dynamic Resource Allocation for Distributed Systems and Cloud Computing," 2020.

[15] H. Shukur, S. Zeebaree, R. Zebari, D. Zeebaree, O. Ahmed, and A. Salih, "Cloud Computing Virtualization of Resources Allocation for Distributed Systems," J. Appl. Sci. Technol. Trends, vol. 1, no. 3, pp. 98-105, 2020.

[16] W. Voorsluys, J. Broberg, and R. Buyya, "Introduction to cloud computing," Cloud Comput. Princ. Paradig., pp. 1-44, 2011.

[17] “Enterprise Resource Planning Systems and Challenges," Technol. Rep. Kansai Univ., vol. 62, no. 4, pp. 18851894, Apr. 2020.

[18] S. R. M. Zeebaree, H. M. Shukur, L. M. Haji, R. R. Zebari, K. Jacksi, and S. M.Abas, "Characteristics and Analysis of Hadoop Distributed Systems,” Technol. Rep. Kansai Univ., vol. 62, no. 4, pp. 1555-1564, Apr. 2020.

[19] O. Alzakholi, L. Haji, H. Shukur, R. Zebari, S. Abas, and M. Sadeeq, "Comparison Among Cloud Technologies and Cloud Performance,” J. Appl. Sci. Technol. Trends, vol. 1, no. 2, Art. no. 2, Apr. 2020, doi: 10.38094/jastt1219.

[20] S. A. de Chaves, B. Carlos, C. M. Westphall, and G. A. Gerônimo, "Customer security concerns in cloud computing," in Proceedings of the Tenth International Conference on Networks (ICN), 2011, pp. 7-11. 
Pavel Y. Abdullah, Subhi R. M. Zeebaree, Karwan Jacksi, and Rizgar R. Zeabri.

[21] K. Choochote and K. Chochiang, "Electronic human resource management (e-hrm) of hotel business in Phuket,” Int. J. Adv. Comput. Sci. Appl., vol. 6, no. 4, pp. 73-78, 2015.

[22] T. T. Weeramanthrie, C. N. Thilakumara, K. Wijesiri, N. I. Fernando, S. Thelijjagoda, and A. Gamage, "ARROW: A web-based employee turnover analysis tool for effective human resource management in large-scale organizations," in 2017 National Information Technology Conference (NITC), 2017, pp. 136-140.

[23] S. Selvi et al., "HR e-Leave Tour Management System at RDCIS, SAIL," in 2014 International Conference on Information Technology, 2014, pp. 333-338.

[24] G. Ying and G. Xiao-hui, "J2EE-based human resources s management information system design and implementation," in 2009 2nd IEEE International Conference on Computer Science and Information Technology, 2009, pp. 25-28.

[25] L. Ma and M. Ye, "The role of electronic human resource management in contemporary human resource management," Open J. Soc. Sci., vol. 3, no. 04, p. 71, 2015.

[26] O. A. Randle, A. Coleman, and R. Kekwaletswe, "Towards a motivational based model for effective use of human resource information system in South African Universities," in 2017 International Conference on Information Society (i-Society), 2017, pp. 61-67.

[27] E. Y. Vinogradova, S. L. Andreeva, A. V. Babkin, and A. I. Galimova, "Corporate information system-Element of efficient human resources management of the industrial-economic complex," in 2017 IEEE VI Forum Strategic Partnership of Universities and Enterprises of Hi-Tech Branches (Science. Education. Innovations) (SPUE), 2017, pp. 63-66.

[28] M. Saini and K. Kaur, "A review of open source software development life cycle models," Int. J. Softw. Eng. Its Appl., vol. 8, no. 3, pp. 417-434, 2014.

[29] J. Vocell, "A Beginner's Guide to SSL: What It Is \& Why It Makes Your Website More Secure." https://blog.hubspot.com/marketing/what-is-ssl (accessed Jun. 03, 2020).

[30] "Cloud Security - Amazon Web Services (AWS)," Amazon Web Services, Inc. https://aws.amazon.com/security/ (accessed Jun. 03, 2020).

[31] S. C. Peres, T. Pham, and R. Phillips, "Validation of the system usability scale (SUS) SUS in the wild," in Proceedings of the Human Factors and Ergonomics Society Annual Meeting, 2013, vol. 57, no. 1, pp. 192-196. 